\title{
Professionalising health professions education
}

\section{The demand for education expertise in teaching and learning}

Teaching competencies are not innate and years of 'teaching experience' do not necessarily produce educationally sound teaching practices that translate into effective and efficient learning. This is true of health professions education (HPE) in the classroom, the laboratory and at the bedside. The plethora of academic staff (faculty)-development initiatives, ranging from short courses to doctoral qualifications, bears testimony to the fact that teaching expertise is a non-negotiable competency of the modern educator Based on the current literature, most formal academic qualifications in HPE are offered by academic institutions in economically wealthy countries. The mandate for HPE training opportunities that are more broadly nuanced to the needs of resource-aware communities is clear.

\section{The need for educators who change education}

While there are many descriptions and inventories articulating the traditional knowledge, skills and attributes of the 'good teacher', limited attention has been paid to the essential leadership and scholarship skills that are needed by the successful educator. Most training programmes, particularly at the certificate and diploma level, focus the bulk of their time on the 'nuts and bolts' of educational practice. They pay little attention to the parallel demand for educators who can both offer and implement educational innovation. This need to pioneer new approaches and lead educational advances, the core functions of a so-called 'change agent', requires training, as it is also not an innate ability of those who work in HPE. This is perhaps most relevant in less well-resourced environments where teachers are appointed to, or implicitly expected to, drive processes that are intended to advance and improve educational practices in their local settings. The observation that educational innovation and leadership are two sides of the same coin is an emerging property of educational training programmes going forward.

\section{Research expertise should be the corner- stone of educational practice}

The scholarship of teaching and learning, that is training initiatives underpinned by research, is no less important in education than it is in medicine. The plethora of traditional teaching and learning activities that are 'historically' derived and perpetuated is slowly being replaced by approaches for which there are at least theoretical frameworks and empiric supporting data. This means that HPE practitioners are obliged to develop some level of research expertise to underpin their daily practice. This may seem a daunting task for busy clinicians who are already engaged in full-time clinical practice, bedside teaching, management, administration and discipline-specific research. Non-degree HPE faculty development initiatives, which tailor this aspect of their programmes to make it a realistic and achievable goal, will gain considerable popularity. 'Dipping a toe' in educational research methodology and the discipline of conducting a small but credible piece of research outside the field of expertise of busy clinicians, is a highly desirable outcome of HPE training initiatives, and creative ways of doing so are becoming increasingly apparent.

\section{The impact of education expertise on students and patients}

One of the key questions asked of faculty development programmes in HPE is whether they have an impact on the key stakeholders of the educational process - the students and patients they care for during their careers. This is a complex question and there are many facets that require further exploration to provide a comprehensive answer. Nonetheless, there is emerging evidence that good teaching makes a difference to students, at least in the classroom and at the bedside. That patients ultimately benefit from the endeavours of those who dedicate time and energy to educating the next generation of healthcare practitioners is an important next step and early efforts may be enlightening and guide future work. The mandate for such research is clear.

\section{Prof. Vanessa Burch}

Editor: African Journal of Health Professions Education vcburch.65@gmail.com

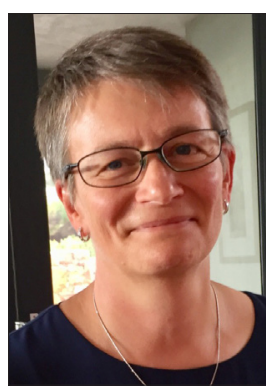

\section{Dr John Norcini}

President: Foundation for the Advancement of International Medical Education and Research (FAIMER) jnorcini@faimer.org

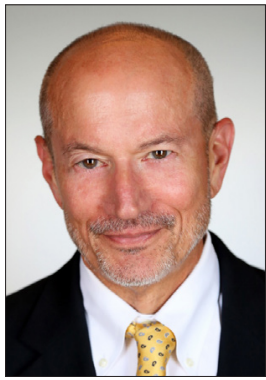

Afr J Health Professions Educ 2019;11(1):2. DOI:10.7196/AJHPE.2019.v1111.1209 